\title{
STUDY OF THE DISTRIBUTION OF WEALTH IN THE MIDDLE AND TOP SEGMENTS OF THE POPULATION OF GEORGIA
}

\section{QETEVAN PIPIA}

Phd student

Samtskhe-Javakheti State University, Georgia

qetino.pipia@gmail.com

\section{KEYWORDS: PARETO DISTRIBUTION, LOGNORMAL DISTRIBUTION, MODELS OF ECONOMICAL LAYERS OF SOCIETY}

For citation: Pipia Q. (2019), Study Of The Distribution Of Wealth In The Middle And Top Segments Of The Population Of The Population Of Georgia, Globalization And Business, №7, pp. 130-142. https://doi.org/10.35945/gb.2019.07.016

Due to social, economic, political and other differences, the distribution of the population by income is a subject of different laws of distributions, for example, of a normal distribution, a log-normal distribution, Pareto distribution, and so on. In some countries the distribution of elements of society by income per unit of time in the lower and middle groups will be close to normal [10] (later it turned out that the distribution of income in the lower and middle groups better described by a log-normal distribution). The Italian economist Wilfredo Pareto remarked that in the richer segments of society, the income corresponding to the elements of society would be much higher than in the case of a normal distribution, because the large income, in contrast to the small and medium, makes it possible to invest in growth. The study of this phenomenon led to a distribution with two parameters, which is also found in statistics, sociology, etc., and is called the Pareto distribution [1].

The following distribution with two parameters $a$ and $v$ is called Pareto distribution:

$$
f=\frac{a}{x^{v}} \text {. }
$$

In [10] the structure of society consisting of three groups is considered: the bottom $10 \%$, with the average distribution of GDP I (low), the average $80 \%$ with the average distribution of GDP $\mathrm{m}$ (middle), the top $10 \%$, - with the average distribution of GDP $t$ ( top). If we denote the share of GDP per capita by $d$, then we get the balance equation

$$
0,1 l+0,8 m+0,1 t=d \text {. }
$$

Indeed,

$$
l=\frac{G D P(\text { low })}{N_{\text {low }}}=\frac{G D P(\text { low })}{0.1 N}, \quad m=\frac{G D P(\text { middle })}{N_{\text {middle }}}=\frac{G D P(\text { middle })}{0.8 N}, \quad t=\frac{G D P(\text { top })}{N_{\text {top }}}=\frac{G D P(\text { top })}{0.1 N},
$$

and it follows the equality (1):

$$
0,1 l+0,8 m+0,1 t=\frac{G D P(\text { low })}{N}+\frac{G D P(\text { middle })}{N}+\frac{G D P(\text { top })}{N}=\frac{G D P}{N}=d .
$$

The ratio of funds is defined as the ratio of incomes of the same number population, but belonging to different income groups. When $10 \%$ is selected from the upper and lower levels, this ratio is called decile ratio [8].

In the United States, the ratio of the upper $90 \%-95 \%$ layer to the lower $5 \%$ layer is often considered [4] since the incomes of the upper $5 \%$ layer are subject of other laws of distribution. This ratio is called the rank coefficient. We will consider the ratio of the incomes of the upper $10 \%$ stratum to the incomes to the lower $10 \%$ stratum, i.e. decimal coefficient D. Since the number of people in these groups is the same, this ratio is equal to the ratio of the average incomes of these groups:

$$
D=\frac{t}{l}
$$

Then from (Error! Reference source not found.) it follows 


$$
0,1(D+1) l+0.8 m=d
$$

If $N$ is a size of a population, then the GDP consumed by the lower, middle and upper groups (respectively $Q_{l}, Q_{m}, Q_{t}$ ) will be

and therefore

$$
Q_{l}=0,1 N l, \quad Q_{m}=0,8 N m, \quad Q_{t}=0,1 N t=0,1 N D l
$$

there $Q$ is the GDP.

$$
Q_{l}+Q_{m}+Q_{t}=Q=N d
$$

Let us suppose that the number $f$ of members of the top layer who has an income $q$ is expressed by the Pareto distribution

$$
f=\frac{a}{q^{v}}
$$

there $a>0, v>2$.

Proposition 1. Let $q_{t}$ be the minimal income of members of the top group, $N_{t}$ be the number of individuals who has the income more or equal to $q_{t}, q_{n} \geq q_{t}, N_{n}$ is the number of individuals who has the income more or equal to $q_{n}$. Then

Proof. It is clear, that

$$
N_{n}=N_{t}\left(\frac{q_{t}}{q_{n}}\right)^{v-1}
$$

$$
q f=\frac{a}{q^{v-1}}
$$

is the income of $f$ members of the top group. Then from (2) and (3) we get difeerential equations

$$
\frac{d N}{d q}=\frac{a}{q^{v}}, \quad q \frac{d N}{d q}=\frac{d Q}{d q}=\frac{a}{q^{v-1}} .
$$

Let $q_{\max }$ be a maximal income in the top gorup. Then

$$
N_{n}=\int_{q_{n}}^{q_{\max }} \frac{a}{q^{v}} d q, \quad Q_{n}=\int_{q_{n}}^{q_{\max }} \frac{a}{q^{v-1}} d q .
$$

Since no one has an income more than $q_{\max }$, we can assume that the upper bound in the integral is infinite:

$$
\begin{gathered}
N_{n}=\int_{q_{n}}^{\infty} \frac{a}{q^{v}} d q=\frac{a}{(v-1) q_{n}^{v-1}}, \\
Q_{n}=\int_{q_{n}}^{\infty} \frac{a}{q^{v-1}} d q=\frac{a}{(v-2) q_{n}^{v-2}} .
\end{gathered}
$$

After calculations we get

From these formulas it follows

$$
\begin{gathered}
N_{n}=\int_{q_{n}}^{\infty} \frac{a}{q^{v}} d q=\left.\frac{a q^{1-v}}{1-v}\right|_{q_{n}} ^{\infty}=\frac{a}{(v-1) q_{n}^{v-1}}, \\
Q_{n}=\int_{q_{n}}^{\infty} \frac{a}{q^{v-1}} d q=\left.\frac{a q^{2-v}}{2-v}\right|_{q_{n}} ^{\infty}=\frac{a}{(v-2) q_{n}^{v-2}}
\end{gathered}
$$

$$
Q_{n}=\frac{a}{(v-2) q_{n}^{\nu-2}}=\frac{a}{(v-1) q_{n}^{\nu-1}} \frac{(v-1) q_{n}^{\nu-1}}{(v-2) q_{n}^{\nu-2}}=\frac{v-1}{v-2} N_{n} q_{n}
$$

Now let $q_{n}=q_{t}$, where $q_{t}$ is the minimal income of the top layer (equivalently the maximal income of the middle layer). Then

$$
\begin{aligned}
N_{t} & =\frac{a}{(v-1) q_{t}^{\nu-1}} \\
Q_{t} & =\frac{a}{(v-2) q_{t}^{\nu-2}}
\end{aligned}
$$

Let us express $a$ by $N_{t}$ from (9) and substitute in (6). Then we get

We can write (6) and (8) shortly as

$$
N_{n}=\frac{a}{(v-1) q_{n}^{v-1}}=\frac{N_{t}(v-1) q_{t}^{\nu-1}}{(v-1) q_{n}^{v-1}}=N_{t}\left(\frac{q_{t}}{q_{n}}\right)^{v-1} .
$$

$$
\begin{gathered}
N_{n}=N_{t}\left(\frac{q_{t}}{q_{n}}\right)^{v-1}, \\
Q_{n}=\frac{v-1}{v-2} N_{n} q_{n} .
\end{gathered}
$$


The proposition is proved.

The formula of the sconomic structure of the upper layer of the society:

Let $q_{t}$ be a minimal income of the top layer, $N_{t}$ be the number of the individuals which has the income more or equal to $q_{t}$. Then

a) The number of individuals who have the income more or equal to $q_{n}$ and its whole income are respectively

$$
N_{n}=N_{t}\left(\frac{q_{t}}{q_{n}}\right)^{v-1}, Q_{n}=\frac{v-1}{v-2} N_{n} q_{n}
$$

b) The number of individuals whose income are between $q_{n_{1}}$ and $q_{n_{2}}$, is

and its whole income is

$$
N_{n_{2}}-N_{n_{1}}=N_{t}\left(\left(\frac{q_{t}}{q_{n_{2}}}\right)^{v-1}-\left(\frac{q_{t}}{q_{n_{1}}}\right)^{v-1}\right)=N_{t} q_{t}^{v-1}\left(\frac{1}{q_{n_{2}}^{v-1}}-\frac{1}{q_{n_{1}}^{v-1}}\right),
$$

The average income of top layer is

$$
Q_{n_{2}}-Q_{n_{1}}=\frac{v-1}{v-2}\left(N_{n_{2}} q_{n_{2}-} N_{n_{1}} q_{n_{1}}\right)
$$

$$
t=\frac{Q_{t}}{N_{t}}
$$

Corollary. Two parameters of Pareto distribution and other parameters are interlinked by formulas:

Proof. Let us write (12) for $Q_{t}$ :

$$
v=\frac{2 Q_{t}-N_{t} q_{t}}{Q_{t}-N_{t} q_{t}}=\frac{2 t-q_{t}}{t-q_{t}}=2+\frac{q_{t}}{t-q_{t}}>2, a=(v-1) q_{t}^{v-1} N_{t}
$$

$$
Q_{t}=\frac{v-1}{v-2} N_{t} q_{t}
$$

Now we must take into account that $Q_{t}=t N_{t}$. The second formula follows from (8).

Since usually $N_{t}$ and $q_{t}$ are known from practice, by these formulas we may calculate the parameters of Pareto distribution $v$ and $a$. If we substitute these expressions in (4), we get the following differential equations

$$
\frac{d N}{d q}=\frac{(v-1) N_{t}}{q_{t}}\left(\frac{q_{t}}{q}\right)^{v}, \frac{d Q}{d q}=(v-1) N_{t}\left(\frac{q_{t}}{q}\right)^{v-1} .
$$

Let us write (13) and (12) for $Q_{t}$ and $N_{t}$. Then the division of (12) on (11) give us the average income of the top layer $t$ :

$$
\frac{Q_{t}}{N_{t}}=\frac{v-1}{v-2} q_{t}=\bar{q}=t
$$

Let us suppose that the boundary values of low, middle and top layers are interlinked by each other by parameters $\alpha, \beta, \gamma$ :

$$
\text { Lower boundary of the low group } q_{l}=\frac{l}{\alpha} \text {; }
$$

Top boundary of the low group (since $l$ is small enough than $m$ ) $q_{m}=\frac{l+m}{\beta} \approx \frac{m}{\beta}=$

$$
\text { = Lower boundary of the middle group; }
$$

Top boundary of the middle group $=$ Lower boundary of the top group $q_{t}=\frac{\gamma m}{\beta}$.

The ratio of the top and lower boundaries of the middle group is

$$
\frac{\gamma m}{\beta}: \frac{l+m}{\alpha}=\frac{\alpha \gamma m}{\beta(l+m)} \approx \frac{\alpha \gamma}{\beta},
$$

since $l$ is small enough than $m$.

Let us substitute $q_{t}=\frac{\gamma m}{\beta}$ in (14):

$$
\frac{v-1}{v-2} q_{t}=\frac{v-1}{v-2} \frac{\gamma m}{\beta}=t, \quad \frac{v-1}{v-2}=\frac{\beta t}{\gamma m} ;
$$

If we suppose that $m=k l$ for some $k$, when we may estimate $D$ :

$$
\frac{v-1}{v-2}=\frac{\beta t}{\gamma m}=\frac{\beta t}{\gamma k l}, \quad D=\frac{t}{l}=\frac{\gamma k}{\beta} \frac{v-1}{v-2} .
$$

From this expression it is clear that the distribution in the top layer depends on the distribution in the low layer.

For example, let be

$$
\alpha=\beta=2, \gamma=3 \text {. }
$$

Then from (16) we get that the ratio of the top and low boundaries of the middle layer is $\gamma$. Then 
Lower boundary of the low group $q_{l}=\frac{l}{2}$;

Top boundary of the low group (since $l$ is small enough than $m$ ) $q_{m}=\frac{l+m}{2} \approx \frac{m}{2}=$

= Lower boundary of the middle group;

Top boundary of the middle group $=$ Lower boundary of the top group $q_{t}=\frac{3 m}{2}$.

Let us remark that in some countries, for example for the USA [10] such a choise of $\gamma$ is justified because a ratio of the top and low boundaries of the middle group is equal to $\gamma=3$.

The analysis of the above theoretical conclusions shows that for their application it is necessary to know the boundary between the middle and upper levels $q_{t}$ and the number of individuals in the upper layer $N_{t}$. It is not necessary that the top layer consist of 10 percent of the population.

Let us apply this results to Georgia. According to the World Bank [5], the population of Georgia in 2017 was distributed by Gross Domestic Product (GDP) as follows:

Distribution of the population (\%) according to GDP consumption in Georgia

$\begin{array}{rrrrrrrr}20176 . & 10 \% & 20 \% & 20 \% & 20 \% & 20 \% & 20 \% & 10 \% \\ & 2.6 & 6.7 & 11.5 & 16 & 22.2 & 43.6 & 28.1\end{array}$

From this list it follows that decile ratio is

$$
D=\frac{28.1}{2.6}=10.8 \approx 11
$$

The middle group consists with $80 \%$ of population and GDP consumed by him is

$$
(6.7-2.6)+11.5+16+22.2+(43.6-28.1)=69.3 \%
$$

Therefore the share of low, middle and top layers in GDP is equal respectively

$$
\frac{2.6}{10}=0.26, \quad \frac{69.3}{80}=0.86625, \quad \frac{28.1}{10}=2.81 .
$$

According to Geostat, the population of Georgia, GDP and GDP by purchasing power in 2017 were respectively

$$
N=3700000, \quad G D P=14,100,000,000 \$, G D P_{\text {purch }}=37,600,000,000 \$ \text {. }
$$

As a result, purchasing power coefficient in 2017 was

$$
\frac{37,600,000,000}{14,100,000,000}=2.67 \text {. }
$$

GDP per capita (by nominal and purchasing power) will be in Georgia

Since $10 \%$ and $80 \%$ of population are

$$
d=\frac{14,100,000,000}{3,700,000}=3810.811 \$, d_{\text {purch }}=\frac{37,600,000,000}{3,700,000}=10162.1622 \$ .
$$

\begin{tabular}{|r|r|}
\hline $0.1 \mathrm{~N}$ & $0.8 \mathrm{~N}$ \\
\hline 370000 & 2960000 \\
\hline
\end{tabular}

then for one representative of the population from the lower, middle and upper layers GDP is distributed approximately as follows (in dollars):

The same dates by purchasing power are equal to

$$
\begin{aligned}
l=\frac{14100000000 \cdot 0.26}{370000} & =990.81, \quad m=\frac{14100000000 \cdot 0.86625}{2960000}=3301.115, \\
t & =\frac{14100000000 \cdot 2.81}{370000}=10708.38 .
\end{aligned}
$$

$$
l_{\text {purch }}=2642, \quad m_{\text {purch }}=8803, \quad t_{\text {purch }}=28556 .
$$

In this example, we limit ourselves to nominal GDP.

By (17) the top bound of the consumption of GDP per capita in middle group, that is equal to the lower bound of the consumption of GDP per capita in top group is

$$
q_{t_{1}}=\frac{3 m}{2}=\frac{3 \cdot 3301}{2}=4952 \text {. }
$$

Similarly, the top bound of the consumption per capita in the middle group i.e. the lower bound of the consumption per capita in the top group (by purchasing power) is

$$
q_{t, \text { purch }_{1}}=\frac{3 m_{\text {purch }}}{2}=\frac{3 \cdot 8803}{2}=13204.46 .
$$


Now let's try to evaluate $q_{t}$ using some well-known economic indicator. According to [12] the subjective margin of wellbeing of one household in the upper middle class in 2017 was 1978 GEL per month. Since one household in Georgia consists approximately of 3.3 persons [13], then the subjective margin of well-being per capita in the upper middle class is 1978:3.3=599.394 GEL per month, and 599.394x12=7192.727 GEL per year. The dollar rate in 2017 was an average of 2.5 [11]. Therefore the subjective margin of well-being per capita in the upper middle class per year is 7192.727:2.5=2877.091\$. If we hypothesize that GDP per person is 1.5 times higher than its direct income, then we will get the maximum income of the upper middle class, that is, the lower boundary of the upper stratum

$$
q_{t_{2}}=2877.091 \times 1.5=4315.636 \$
$$

and because

$$
q_{t, \text { purch }_{2}}=11508.364 \text {. }
$$

If we substitues values of $q_{t_{1}}$ and $q_{t_{2}}$ in first formula of (14), we get two values of $v$ :

$$
v_{1}=2.860, \quad v_{2}=2.675 \text {. }
$$

The income of top groups will be

$$
\begin{gathered}
Q_{t}=0.281 \cdot 14,100,000,000=3,962,100,000, \\
Q_{t, \text { purch }}=0.281 \cdot 37,600,000,000=10,565,600,000,
\end{gathered}
$$

and number of members of top group will be

$$
N_{t}=3,700,000 \cdot 0.1=370,000 .
$$

Now we hypothesize that the rich stratum of the society in Georgia is described by the Pareto distribution - this hypothesis is widespread and is confirmed in the works of many authors, for example in [1], [9], [10]. The fact is that the exponent $e^{-\frac{x^{2}}{2}}$ decreases faster than the power function $\frac{1}{q^{v-1}}, v>2$. Therefore, Pareto distribution decreases more slowly than the normal distribution. This adequately reflects the fact that high returns allow you to invest.

As we know $q_{t_{1}}=4951.672 \$$. Let us compute the number of persons which share in GDP exceeds $10,000 \$$. This means that $q_{1}=10,000$. Formula (11) get

$$
N_{1}=N_{t}\left(\frac{q_{t_{1}}}{q_{1}}\right)^{\nu_{1}-1}=370000 *\left(\frac{4,951.672297}{10,000}\right)^{2.86-1} \approx 100090 .
$$

Also by formula (12) we have

$$
Q_{1}=\frac{v-1}{v-2} N_{1} q_{1}=\frac{2.86-1}{2.86-2} \cdot 100090 \cdot 10,000=2,164,532,303,
$$

which means that the share in GDP of 100090 persons exceeds $10,000 \$$, and they consume from GDP 2,164,532,303\$. In the lists below, the distribution of GDP (according to the nominal and the purchasing power) is calculated when the share of one person in GDP is more than $10,000 \$$, more than $100,000 \$$, more than $1,000,000 \$$, more than $10,000,000 \$$ and more than $100,000,000 \$$. From these tables, in particular, we can conclude that in Georgia's economy it is impossible to generate $10,000,000$ dollars during a year!

Now let us do the same calculations for $q_{t_{2}}=4315.636 \$$. As we know in this case $v_{2}=2.675$. We have:

$$
\begin{gathered}
N_{1}=N_{t}\left(\frac{q_{t_{2}}}{q_{1}}\right)^{v_{2}-1}=370000 *\left(\frac{4315.636}{10,000}\right)^{2.675-1} \approx 90546 ; \\
Q_{1}=\frac{v-1}{v-2} N_{1} q_{1} \frac{2.675-1}{2.675-2} \cdot 90546 \cdot 10,000=2,246,726,101 .
\end{gathered}
$$

\begin{tabular}{|r|r|r|r|r|r|r|r|r|r|r|}
\hline $\mathrm{t}$ & $\mathrm{qt}$ & $\mathrm{Nt}$ & $\mathrm{Qt}$ & $\mathrm{niu}$ & $\mathrm{q1}$ & $\mathrm{N1}$ & $\mathrm{Q1}$ & $\mathrm{q} 2$ & $\mathrm{N2}$ & Q2 \\
\hline 10708.38 & 4951.672 & 370000 & 3962100000 & 2.86015722 & 10000 & 100090.4 & 2164532303 & 100000 & 1381.131526 & 298680487.7 \\
\hline 28555.68 & 13204.46 & 370000 & 10565600000 & 2.86015722 & 20000 & 170922 & 7392643442 & 100000 & 8562.564407 & 1851721480 \\
\hline 10708.38 & 4315.636 & 370000 & 3962100000 & 2.675083767 & 10000 & 90546.42 & 2246726101 & 100000 & 1913.319504 & 474751519.4 \\
\hline 28555.68 & 11508.36 & 370000 & 10565600000 & 2.675083767 & 20000 & 146606.8 & 7275502195 & 100000 & 9892.835954 & 2454707063 \\
\hline
\end{tabular}




\begin{tabular}{|r|r|r|r|r|r|r|r|r|}
\hline \multicolumn{3}{|c|}{ domom6o } & \multicolumn{2}{|c|}{10 dom } & \multicolumn{2}{|c|}{100 dom } \\
\hline q3 & N3 & Q3 & q4 & N4 & Q4 & q5 & N5 & Q5 \\
\hline 1000000 & 19.05802178 & 41214461.72 & 10000000 & 0.262979 & 5687120 & 100000000 & 0.003629 & 784757 \\
\hline 1000000 & 118.153511 & 255516202.8 & 10000000 & 1.630382 & 35258288 & 100000000 & 0.022497 & 4865237 \\
\hline 1000000 & 40.42999906 & 100318861.8 & 10000000 & 0.854319 & 21198192 & 100000000 & 0.018052 & 4479351 \\
\hline 1000000 & 209.043679 & 518699590 & 10000000 & 4.417263 & $1.1 E+08$ & 100000000 & 0.09334 & 23160523 \\
\hline
\end{tabular}

If we compute $a$ for example, in the case $q_{t_{1}}$, we will get a huge number:

$$
a=(v-1) q_{t_{1}}^{v-1} N_{t}=5,128,692,385,795.29868 .
$$

A density of a lognormal distribution is

and a cumulative distribution function [9] is

$$
f(x)=\frac{1}{x \sigma \sqrt{2 \pi}} e^{-\frac{(\ln x-\mu)^{2}}{2 \sigma^{2}}}
$$

$$
F(x)=\frac{1}{\sigma \sqrt{2 \pi}} \int_{0}^{x} \frac{1}{x} e^{-\frac{(\ln x-\mu)^{2}}{2 \sigma^{2}}} d x .
$$

In the lognormal distribution a logarithm of a variables has a normal distribution. Indeed, in this case we must have

$$
F(x)=\frac{1}{\sigma \sqrt{2 \pi}} \int_{0}^{x} e^{-\frac{(\ln x-\mu)^{2}}{2 \sigma^{2}}} d(\ln x)=\frac{1}{\sigma \sqrt{2 \pi}} \int_{0}^{x} \frac{1}{x} e^{-\frac{(\ln x-\mu)^{2}}{2 \sigma^{2}}} d x .
$$

The log-normal distribution has two parameters: $\mu$ @s $\sigma>0$.

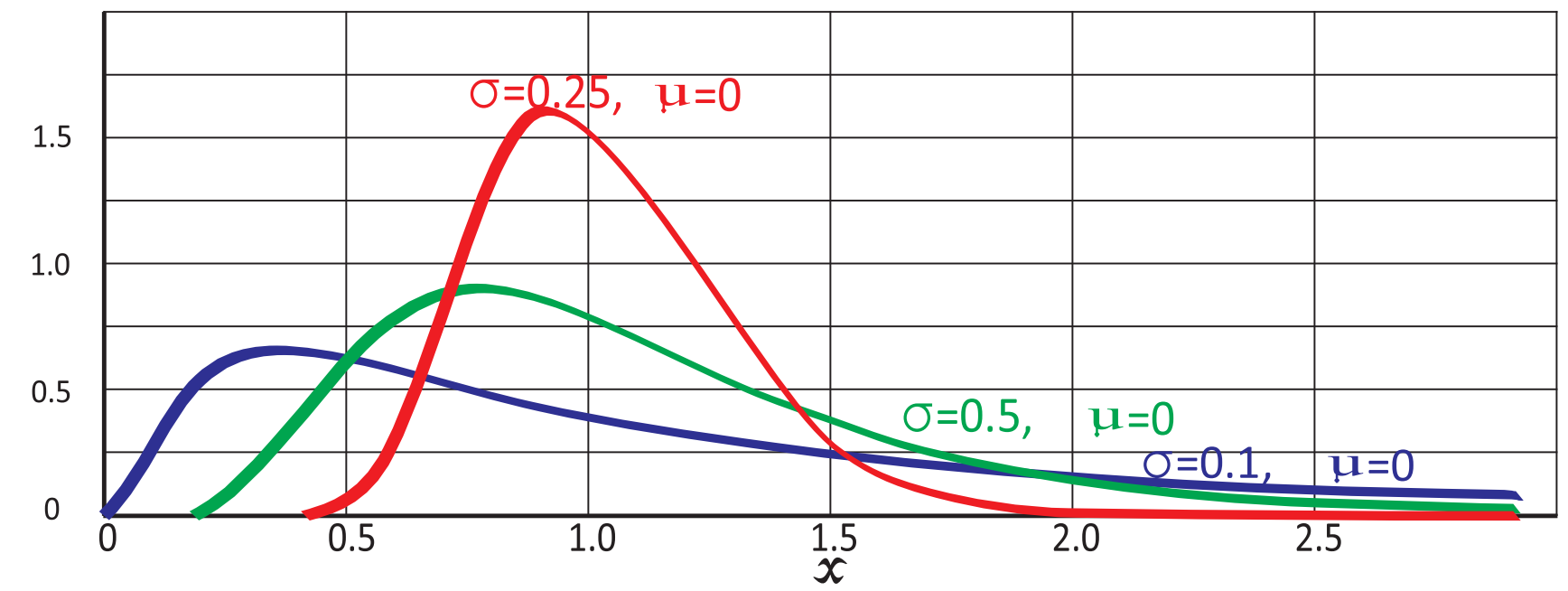

Picture 1.

The lognormal distribution is right asymmetric - it reduces slowly on the right (see Picture 1). In order to obtain the density of a distribution characterized by a left asymmetry, one must consider a distribution whose density is obtained by mirroring the density of the lognormal distribution with respect to a straight line passing through the mode parallel to the oY axis. Since the mode of the lognormal distribution is

$$
X_{\text {mod }}=e^{\mu-\sigma^{2}} \text {, and } K_{x}=X_{c} / X_{\text {mod }},
$$

then the density and the cumulative distribution function of left-asymmetric distribution will be

$$
\begin{gathered}
f(x)=\frac{1}{\left(2 e^{\mu-\sigma^{2}}-x\right) \sigma \sqrt{2 \pi}} e^{-\frac{\left(\ln \left(e^{\mu-\sigma^{2}}-x\right)-\mu\right)^{2}}{2 \sigma^{2}}}, \\
F(x)=\frac{1}{\sigma \sqrt{2 \pi}} \int_{0}^{x} \frac{1}{\left(2 e^{\mu-\sigma^{2}}-x\right)} e^{-\frac{\left(\operatorname { l n } \left(e^{\left.\left.\mu-\sigma^{2}-x\right)-\mu\right)^{2}}\right.\right.}{2 \sigma^{2}}} d x .
\end{gathered}
$$

See the plot of the density of the left-asymmetric distribution in Picture 2 below when $a=1, \sigma=1$. 


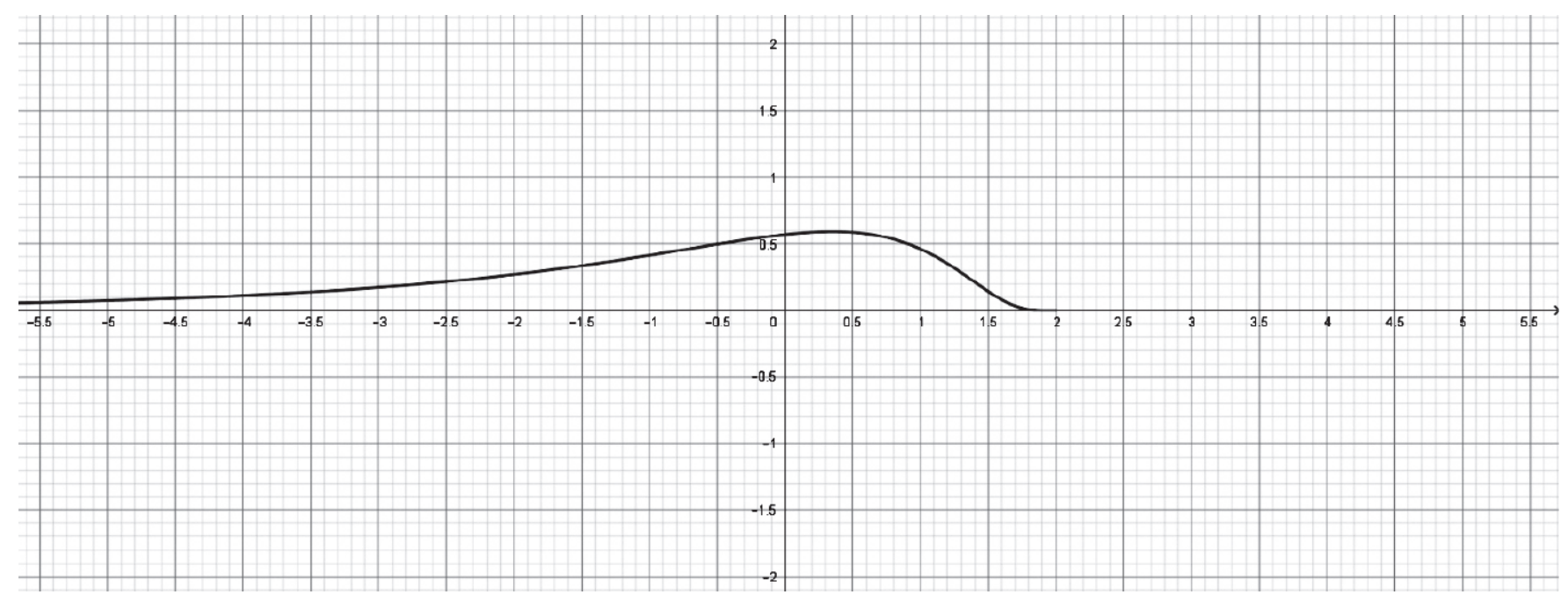

Picture 2.

Methods for computation of lognormal distribution parameters are described, for example, in [9]. Suppose we know the average monthly salary $X_{c}$ (which is calculated by counting macroparameters and size of the population) and the value of the logical function when the upper bound of the integral is $x_{i}$ :

$$
\frac{1}{\sigma \sqrt{2 \pi}} \int_{0}^{x_{i}} \frac{1}{x} e^{-\frac{\left(\ln (x-\mu)^{2}\right.}{2 \sigma^{2}}} d x=F\left(x_{i}\right)
$$

Let us try to calculate the values of $\mu$ and $\sigma$. Since a mean of the lognormal distribution is

then [9]

$$
E(X)=e^{\mu+0.5 \sigma^{2}}
$$

$$
X_{c}=e^{\mu+0.5 \sigma^{2}} .
$$

(18) and (19) give the system of two equations with two variables

$$
\left\{\begin{array}{c}
\frac{1}{\sigma \sqrt{2 \pi}} \int_{0}^{x_{i}} \frac{1}{x} e^{-\frac{(\ln (x-\mu))^{2}}{2 \sigma^{2}}} d x=F\left(x_{i}\right) \\
e^{\mu+0.5 \sigma^{2}}=X_{c}
\end{array} .\right.
$$

In the first equation of the system (20) let us apply the method of changing the variable

Since

$$
z=\frac{\ln (x-\mu)}{\sigma}
$$

$$
d z=\frac{1}{\sigma x} d x
$$

then

$$
\frac{1}{\sigma \sqrt{2 \pi}} \int_{0}^{x_{i}} \frac{1}{x} e^{-\frac{(\ln (x-\mu))^{2}}{2 \sigma^{2}}} d x=\frac{1}{\sqrt{2 \pi}} \int_{0}^{z_{i}} e^{-\frac{z^{2}}{2}} d z
$$

where

$$
z_{i}=\frac{\ln \left(x_{i}-\mu\right)}{\sigma} .
$$

We got a simpler system:

$$
\begin{gathered}
\frac{1}{\sqrt{2 \pi}} \int_{0}^{z_{i}} e^{-\frac{z^{2}}{2}} d z=F\left(x_{i}\right), \\
e^{\mu-0.5 \sigma^{2}}=X_{c} .
\end{gathered}
$$


In this system we have two variables $\mu$ and $\sigma$, because $z_{i}$ depends on $\mu$.

Consequently

$$
\frac{1}{\sqrt{2 \pi}} \int_{0}^{z_{i}} e^{-\frac{z^{2}}{2}} d z=F\left(x_{i}\right)
$$

With the standard method, for example, by Excel, we can find the value of $z_{i}$ which depends on $F\left(x_{i}\right)$. From the second equation of the system (20) it follows that

Let us substitute (22) in (21):

$$
\mu=\ln X_{c}-0.5 \sigma^{2}
$$

$$
z_{i}=\frac{\ln x_{i}-\ln X_{c}+0.5 \sigma^{2}}{\sigma} .
$$

Then because $\sigma \neq 0$, we get a quadratic equation

$$
\sigma^{2}-2 z_{i} \sigma-2 \ln \left(X_{c} / x_{i}\right)=0,
$$

which solution is

$$
\sigma=z_{i} \pm \sqrt{z_{i}^{2}+2 \ln \left(X_{c} / x_{i}\right)}
$$

Only the positive root is economically significant:

From (22) we get $\mu$ :

$$
\sigma=z_{i}+\sqrt{z_{i}^{2}+2 \ln \left(X_{c} / x_{i}\right)} .
$$

$$
\mu=\ln X_{c}-0.5 \sigma^{2} .
$$

Let us now test the hypothesis that the distribution of the declared income in Georgia is lognormal. To do this, we use the data received from Revenue Service of the Ministry of Finance of Georgia (see also [15]) about the declared incomes of the population of Georgia in 2009-2017:

\begin{tabular}{|c|c|c|c|c|c|c|c|c|}
\hline 2009 & 2010 & 2011 & 2012 & 2013 & 2014 & 2015 & 2016 & 2017 \\
\hline 762,855 & 846,045 & 987,426 & $1,118,636$ & $1,104,222$ & $1,181,484$ & $1,116,625$ & $1,185,065$ & $1,189,718$ \\
\hline
\end{tabular}

List 3. The number of people with declared income, 2009-2017.

\begin{tabular}{|c|c|c|c|c|c|c|c|c|c|}
\hline $1-100$ & $100-200$ & $200-300$ & $300-400$ & $400-500$ & $500-600$ & $600-800$ & $800-1000$ & $\begin{array}{c}1000- \\
1250\end{array}$ & $\begin{array}{c}1250- \\
1666\end{array}$ \\
\hline 205,435 & 135,886 & 93,448 & 79,784 & 47,829 & 34,594 & 51,159 & 32,846 & 25,209 & 23,315 \\
\hline
\end{tabular}

\begin{tabular}{|c|c|c|c|c|c|c|c|c|c|}
\hline $1666-2083$ & $2083-2500$ & $2500-3333$ & $\begin{array}{c}3333- \\
4166\end{array}$ & $\begin{array}{c}4166- \\
5000\end{array}$ & $\begin{array}{c}5000- \\
5833\end{array}$ & $\begin{array}{c}5833- \\
6666\end{array}$ & $\begin{array}{c}6666- \\
7500\end{array}$ & $\begin{array}{c}7500- \\
8333\end{array}$ & $>8333$ \\
\hline 11,046 & 6,518 & 7,178 & 3,230 & 1,766 & 1,126 & 703 & 472 & 331 & 1,980 \\
\hline
\end{tabular}

List 4. The distribution of the population by declared incomes, 2009

\begin{tabular}{|c|c|c|c|c|c|c|c|c|c|}
\hline $1-100$ & $100-200$ & $200-300$ & $300-400$ & $400-500$ & $500-600$ & $600-800$ & $800-1000$ & $\begin{array}{c}1000- \\
1250\end{array}$ & $\begin{array}{c}1250- \\
1666\end{array}$ \\
\hline 297469 & 134559 & 103185 & 84494 & 75525 & 60955 & 90192 & 63427 & 55643 & 56682 \\
\hline
\end{tabular}

\begin{tabular}{|c|c|c|c|c|c|c|c|c|c|}
\hline $1666-2083$ & $2083-2500$ & $2500-3333$ & $3333-4166$ & $\begin{array}{c}4166- \\
5000\end{array}$ & $\begin{array}{c}5000- \\
5833\end{array}$ & $\begin{array}{c}5833- \\
6666\end{array}$ & $\begin{array}{c}6666- \\
7500\end{array}$ & $\begin{array}{c}7500- \\
8333\end{array}$ & $>8333$ \\
\hline 25878 & 15266 & 15887 & 8093 & 4646 & 2929 & 1937 & 1339 & 1097 & 5128 \\
\hline
\end{tabular}




\begin{tabular}{|c|c|c|c|c|c|c|c|c|c|}
\hline $1-100$ & $100-200$ & $200-300$ & $300-400$ & $400-500$ & $500-600$ & $600-800$ & $800-1000$ & $\begin{array}{c}1000- \\
1250\end{array}$ & $\begin{array}{c}1250- \\
1666\end{array}$ \\
\hline 230,280 & 125,013 & 99,417 & 83,823 & 75,525 & 67,610 & 115,023 & 88,848 & 80,873 & 83,744 \\
\hline
\end{tabular}

\begin{tabular}{|c|c|c|c|c|c|c|c|c|c|}
\hline $1666-2083$ & $2083-2500$ & $2500-3333$ & $3333-4166$ & $4166-5000$ & $5000-5833$ & $5833-6666$ & $6666-7500$ & $7500-8333$ & $>8333$ \\
\hline 42,423 & 24,361 & 27,309 & 14,204 & 8,141 & 5,233 & 3,784 & 2,609 & 1,884 & 9,614 \\
\hline
\end{tabular}

List 6. The distribution of the population by declared incomes, 2017

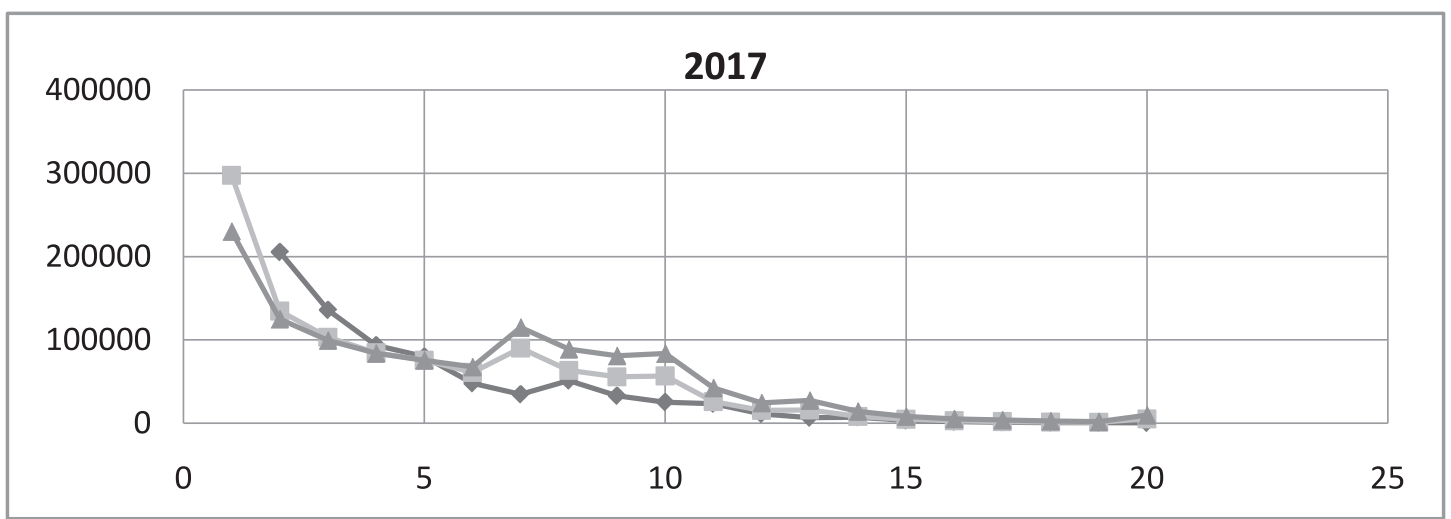

Picture 3. The distribution of the population by declared incomes:

$\diamond-2009, \Delta-2013, \quad \square-2017$

Based on Table 6 we will create a new Table 7:

\begin{tabular}{|c|c|c|c|c|c|c|c|c|c|c|c|}
\hline 2017 & $x_{i}$ & $\mathrm{~N}$ & $\Delta F\left(x_{i}\right) \%$ & $F\left(x_{i}\right) \%$ & $F\left(x_{i}\right)$ & 2017 & $x_{i}$ & $\mathrm{~N}$ & $\Delta F\left(x_{i}\right) \%$ & $\left(x_{i}\right) \%$ & $F\left(x_{i}\right)$ \\
\hline 1 & 0 & & 0 & 0 & 0 & 12 & 2083 & 42423 & 3.565803 & 91.83512 & 0.918351 \\
\hline 2 & 100 & 230280 & 19.35585 & 19.35585 & 0.193558 & 13 & 2500 & 24361 & 2.047628 & 93.88275 & 0.938828 \\
\hline 3 & 200 & 125013 & \begin{tabular}{l|l}
3 & 10.50778
\end{tabular} & 29.86363 & 0.298636 & 14 & 3333 & 27309 & 2.295418 & 96.17817 & 0.961782 \\
\hline 4 & 300 & 99417 & $\begin{array}{ll}7 & 8.35635\end{array}$ & 38.21998 & 0.3822 & 15 & 4166 & 14204 & 1.193896 & 97.37207 & 0.973721 \\
\hline 5 & 400 & 83823 & 37.045619 & 45.2656 & 0.452656 & 16 & 5000 & 8141 & 0.68428 & 98.05635 & 0.980563 \\
\hline 6 & 500 & 75525 & 56.348143 & 51.61374 & 0.516137 & 17 & 5833 & 5233 & 0.439852 & 98.4962 & 0.984962 \\
\hline 7 & 600 & 67610 & 5.682859 & 57.2966 & 0.572966 & 18 & 6666 & 3784 & 0.318059 & 98.81426 & 0.988 \\
\hline 8 & 800 & 115023 & 9.668089 & 66.96469 & 0.669647 & 19 & 7500 & 2609 & 0.219296 & 99.03355 & 0.990336 \\
\hline 9 & 1000 & 88848 & 7.467988 & 74.43268 & 0.744327 & 20 & 8333 & 1884 & 0.158357 & 99.19191 & 0.991919 \\
\hline 10 & 1250 & 80873 & 6.797661 & 81.23034 & 0.812303 & 21 & 16000 & 6014 & 0.505498 & 99.69741 & 0.996974 \\
\hline 11 & 1666 & 83744 & 7.038979 & 88.26932 & 0.882693 & $22>$ & $>16000$ & 3600 & 0.302593 & 100 & 1 \\
\hline
\end{tabular}

List 7.

The first column shows the numbers of the intervals, in the second - the intervals of declared income, in the third - the number of persons corresponding to the intervals. For example, this table shows that the monthly income from 0 to $100 \mathrm{GEL}$ have 230280 people, from 100 to $200 \mathrm{GEL}$ - 125013 people, etc. The fourth column shows how many percent are the third column data from the number of persons with declared income (1189718 person), in the fifth column - the accumulated value of these percent. In the sixth column, these percentages are converted to fractions of a unit.

At first, let us calculate Gini index of the declared monthly income for 2017. Let's agree that when calculating the Gini index we will not take into account incomes exceeding 16,000 GEL per month, since in this case the Gini index will be inadequate. Let us construct the Lorenc curve. In List 8 the data are translated into a convenient form for constructing Lorenz curve: 


\begin{tabular}{|c|c|c|c|c|c|}
\hline$x_{i}$ & $F\left(x_{i}\right)$ & $x_{i}$ & $x_{i} / 16000$ & $F\left(x_{i}\right)$ & $x_{i} / 16000$ \\
\hline 0 & 0 & 0 & & & \\
\hline 100 & 0.193558 & 100 & 0.00625 & 0.193558 & 0.00625 \\
\hline 200 & 0.298636 & 200 & 0.0125 & 0.298636 & 0.0125 \\
\hline 300 & 0.3822 & 300 & 0.01875 & 0.3822 & 0.01875 \\
\hline 400 & 0.452656 & 400 & 0.025 & 0.452656 & 0.025 \\
\hline 500 & 0.516137 & 500 & 0.03125 & 0.516137 & 0.03125 \\
\hline 600 & 0.572966 & 600 & 0.0375 & 0.572966 & 0.0375 \\
\hline 800 & 0.669647 & 800 & 0.05 & 0.669647 & 0.05 \\
\hline 1000 & 0.744327 & 1000 & 0.0625 & 0.744327 & 0.0625 \\
\hline 1250 & 0.812303 & 1250 & 0.078125 & 0.812303 & 0.078125 \\
\hline 1666 & 0.882693 & 1666 & 0.104125 & 0.882693 & 0.104125 \\
\hline 2083 & 0.918351 & 2083 & 0.130188 & 0.918351 & 0.130188 \\
\hline 2500 & 0.938828 & 2500 & 0.15625 & 0.938828 & 0.15625 \\
\hline 3333 & 0.961782 & 3333 & 0.208313 & 0.961782 & 0.208313 \\
\hline 4166 & 0.973721 & 4166 & 0.260375 & 0.973721 & 0.260375 \\
\hline 5000 & 0.980563 & 5000 & 0.3125 & 0.980563 & 0.3125 \\
\hline 5833 & 0.984962 & 5833 & 0.364563 & 0.984962 & 0.364563 \\
\hline 6666 & 0.988143 & 6666 & 0.416625 & 0.988143 & 0.416625 \\
\hline 7500 & 0.990336 & 7500 & 0.46875 & 0.990336 & 0.46875 \\
\hline 8333 & 0.991919 & 8333 & 0.520813 & 0.991919 & 0.520813 \\
\hline 16000 & 0.996974 & 16000 & 1 & 1 & 1 \\
\hline$>16000$ & 1 & $>16000$ & & & \\
\hline
\end{tabular}

List 8 .

Here we divide $\boldsymbol{x}_{\boldsymbol{i}}$ to 16000 , then rearrange $x_{i} / 16000$ and $F\left(x_{i}\right)$. The last two columns will give us a Lorenz curve:

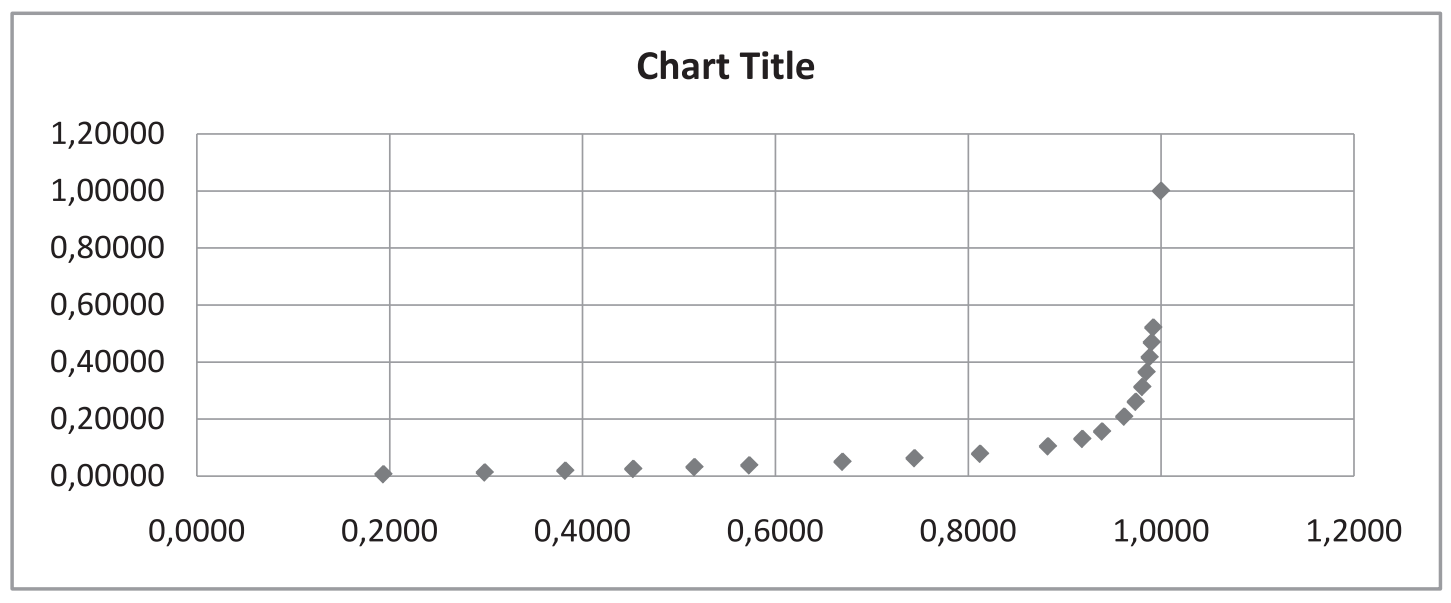

Picture 4

If $p_{i}$ part of population, $i=1,2, \ldots, n, p_{1}+p_{2}+\cdots+p_{n}=1$, owns $q_{i}$ part of a wealth, where $i=1,2, \ldots, n, q_{1}+$ $q_{2}+\cdots+q_{n}=1$, with a cumulative form $s_{i}=q_{1}+q_{2}+\cdots+q_{i}$, then Gini index can be calculated by formula [2]

$$
G=1-\sum_{i=1}^{n} p_{i}\left(s_{i}+s_{i-1}\right) \text {. }
$$

The plot in Picture 4 is almost rectangular, therefore the distribution of declared income is extremely uneven. It is easy to calculate that the Gini index corresponding to the plot on Picture 4 is equal to $\quad G=0.89$. 
According to Geostat [14] the average annual salary in the public and private sectors of Georgia in 2017 was $X_{c}=989$ GEL. For example, let us choose $\mathrm{i}=1$; According to table 3,

$$
F\left(x_{1}\right)=0.193558,
$$

i.e.

By Excel we can calculate that

$$
\frac{1}{\sqrt{2 \pi}} \int_{0}^{z_{1}} e^{-\frac{z^{2}}{2}} d z=0.193558
$$

$$
z_{1}=-0.86486
$$

Since

$$
\ln \left(X_{c} / x_{i}\right)=2.291524 \text {, }
$$

the quadratic equation (23) takes the form

$$
\sigma^{2}+1.72972 \sigma-4.583048291=0 .
$$

It has the positive solution

\begin{tabular}{|c|c|c|c|c|c|c|c|}
\hline $\mathrm{i}$ & $z_{i}$ & $X_{c} / x_{i}$ & $\ln \left(\frac{X_{c}}{c}\right)$ & $\sigma$ & $\mu$ & $X_{\text {mod }}$ & $K_{x}$ \\
\hline 1 & -0.86486 & 9.89 & 2.291524 & 1.444044 & 5.854063 & 43.32801 & 22.82587876 \\
\hline 2 & -0.52833 & 4.945 & 1.598377 & 1.336045 & 6.004186 & 67.97694 & 14.54905095 \\
\hline 3 & -0.29971 & 3.296667 & 1.192912 & 1.273711 & 6.085524 & 86.76335 & 11.39882192 \\
\hline 4 & -0.11895 & 2.4725 & 0.90523 & 1.231827 & 6.137995 & 101.5546 & 9.738605958 \\
\hline 5 & 0.040462 & 1.978 & 0.682086 & 1.20914 & 6.165684 & 110.3508 & 8.962327139 \\
\hline 6 & 0.183931 & 1.648333 & 0.499765 & 1.200474 & 6.176126 & 113.8622 & 8.68593753 \\
\hline 7 & 0.438938 & 1.23625 & 0.212083 & 1.224325 & 6.147208 & 104.4007 & 9.473114755 \\
\hline 8 & 0.656743 & 0.989 & -0.01106 & 1.296422 & 6.05634 & 79.48999 & 12.4418183 \\
\hline 9 & 0.886416 & 0.7912 & -0.2342 & 1.449733 & 5.845832 & 42.27126 & 23.39651375 \\
\hline 10 & 1.188558 & 0.593637 & -0.52149 & 1.796586 & 5.282834 & 7.807727 & 126.6693799 \\
\hline 11 & 1.394067 & 0.474796 & -0.74487 & 2.067625 & 4.759157 & 1.622688 & 609.4826824 \\
\hline 12 & 1.545005 & 0.3956 & -0.92735 & 2.274621 & 4.309745 & 0.421408 & 2346.894138 \\
\hline 13 & 1.771747 & 0.29673 & -1.21493 & 2.613898 & 3.480462 & 0.035014 & 28245.6943 \\
\hline 14 & 1.938529 & 0.237398 & -1.43802 & 2.877604 & 2.756392 & 0.003989 & 247931.6508 \\
\hline 15 & 2.065528 & 0.1978 & -1.6205 & 3.078152 & 2.159184 & 0.000665 & 1487386.178 \\
\hline 16 & 2.169088 & 0.169553 & -1.77459 & 3.244149 & 1.634444 & 0.000138 & 7179570.988 \\
\hline 17 & 2.261717 & 0.148365 & -1.90808 & 3.401544 & 1.111444 & 2.87E-05 & 34475203.52 \\
\hline 18 & 2.339125 & 0.131867 & -2.02596 & 3.530586 & 0.664175 & 7.5E-06 & 131900542 \\
\hline 19 & 2.405241 & 0.118685 & -2.13128 & 3.639183 & 0.274867 & $2.33 \mathrm{E}-06$ & 424101439.1 \\
\hline 20 & 2.744959 & 0.061813 & -2.78365 & 4.147634 & -1.70474 & $6.15 E-09$ & $1.6094 \mathrm{E}+11$ \\
\hline
\end{tabular}

$$
\sigma=1.444044073 .
$$

Then from (22) we have

$$
\mu=\ln 989-0.51 .444044073^{2}=5.85406269 .
$$

The cases $i=2,3, \ldots, 20$ are considered in List 9:

List 9.

For example let us write the lognormal distribution for data from the row 8:

$$
F\left(x_{i}\right)=\frac{1}{1.2964 \sqrt{2 \pi}} \int_{0}^{x_{i}} \frac{1}{x} e^{-\frac{(\ln (x-6.0563))^{2}}{2 * 1.2964^{2}}} d x
$$


From List 9 it is clear that with a certain accuracy it can be argued that the intervals of incomes $300-800$ GEL and 41667500 GEL is described by the log-normal distribution. Such a conclusion can be drawn because the variance and the expectation change at the same time in an insignificant way.

\section{REFERENCES:}

1. Arnold, B. C., (2015). Pareto Distributions. London: CRC Press.

2. Bellu, L. \& Liberati, P., (2006). Inequality and Axioms for its Measurement. N.-Y.: FAO.

3. Cowell, F. A., (2009). Measuring Inequality. London: Oxford University Press.

4. University of Texas., 2018. Measuring Inequality Project. https://utip.lbj.utexas.edu/tutorials.html.

5. World Bank, (2017). Percentage share of income or consumption. http://wdi.worldbank.org/table/1.3.

6. Goskomstat Rossii, (1996). Methodological provisions on statistics. Moscow (in Russian)

7. Kolmakov I. B., (2008). Methods of forecasting poverty indicators, taking into account disadvantaged groups. Problemy Prognozirovania, Issue 5, pp. 95-109 (in Russian).

8. Kolmakov I. B., (2015). Methodology of calculations and analyzes of integral estimates of the polarization of money incomes of the population. Voprosy Statistiki, pp. 23-36 (in Russian).

9. Kolmakov I. B., (2016). Conjugation of the logarithmically normal distribution of the population in terms of household income with the Pareto distribution. Audit i Finansovyj Analiz, pp. 124-131 (in Russian).

10. Rozanov V. B., (2007). Economic structure of the Russian society. In: Econophysics. Moscow, pp. 560-600 (in Russian).

11. 2018. https://m2b.ge. [Online] Available at: https://m2b.ge/post/177009-laris-kursis-dinamika-2017-wels-mizezebi-damolodinebi [Accessed 7 July 2019].

12. Kakulia M., (2018). Middle class in Georgia: quantitative assessment, dynamics And profile. Tbilisi in Georgian).

13. GeoStat, (2016). http://census.ge/. [Online] Available at: http://census.ge/files/results/Census\%20Release_GEO.pdf [Accessed 7 July 2019].

14. GeoStat, (2018). [Online] Available at: http://www.geostat.ge/?action=page\&p_id=148\&lang=geo [Accessed 27092018$].$

15. Tabula, (2018). Only $0.6 \%$ of Georgian population has more than 5,000 GEL per month [Online] Available at: http://tbl. ge/2t1g [Accessed 29. 09. 2018] (in Georgian). 


\section{STUDY OF THE DISTRIBUTION OF WEALTH IN THE MIDDLE AND TOP SEGMENTS OF THE POPULATION OF GEORGIA}

\section{QETEVAN PIPIA}

\section{Phd student}

Samtskhe-Javakheti State University, Georgia qetino.pipia@gmail.com

\section{KEYWORDS: PARETO DISTRIBUTION, LOGNORMAL DISTRIBUTION, MODELS OF ECONOMICAL LAYERS OF SOCIETY.}

For citation: Pipia Q. (2019), Study Of The Distribution Of Wealth In The Middle And Top Segments Of The Population Of The Population Of Georgia, Globalization And Business, №7, pp. 130-142. https://doi.org/10.35945/gb.2019.07.016

\section{SUMMARY}

Due to economic, social, political and other differences, different sectors of society are subject to different laws of distribution. Among these laws are Pareto distribution, the normal distribution, the lognormal distribution, and so on. It is noteworthy that the higher, richer stratum of a society more often depends on the Pareto distribution. As for the poor and middle class, there was an attempt to build their model using a normal distribution. But later it turned out that more accurate results are provided by a lognormal distribution. The article attempts to build a model of the distribution of the upper layers of the population of Georgia in terms of per capita GDP consumption (according to the World Bank) using Pareto distribution. As for the other layers, due to the lack of data in GeoStat, when trying to build a model using a lognormal distribution, data on the population's declared income are used, obtained from the Revenue Service of the Ministry of Finance of Georgia, hoping that this data correlates with the population distribution by GDP consumption. 